\title{
Why Do Dancers Smoke? \\ Smoking, Time Preference, and Wage Dynamics
}

\author{
Lalith Munasinghe \\ Barnard College, Columbia University \\ Nachum Sicherman \\ Columbia University and NBER
}

March 2004

Revised: October 2004

Second revision: February 2005

Lalith Munasinghe

Nachum Sicherman

Department of Economics

Graduate School of Business

Barnard College, Columbia University

Columbia University

New York, NY 10027

New York, NY 10027

We thank Eli Berman, Michael Grossman, George Loewenstein, Chris Paxson, Paolo Siconolfi, Finis Welch, and seminar participants at the Federal Reserve Bank of NY, University of Oregon, Columbia University, Barnard College, CUNY, Texas A\&M, and the Society for Advanced Behavioral Economics conference in San Diego, for many helpful comments and suggestions. We thank Rachel Singal and Jaime Rosenfeld for collecting and analyzing the survey data.

JEL Classification: I12, J22, J24, J31. 


\title{
Why Do Dancers Smoke? \\ Smoking, Time Preference, and Wage Dynamics
}

\begin{abstract}
$\underline{\text { Abstract }}$
The discount rate is a key determinant of investments in human capital and occupational choice. Individuals who are less future oriented - i.e. have a higher discount rate - are less likely to invest in human capital and hence more likely to select into careers with lower and flatter earnings profiles. Since an individual's discount rate is unobservable, we use smoking behavior as a proxy to study the role of discounting on wage dynamics. Using data from the National Longitudinal Surveys of Youth (1979-94) we find that smokers, compared to their non-smoker counterparts, earn lower wages at the time they first enter the labor market and experience substantially lower rates of wage growth in the first decade of their careers. These differences in wage dynamics among smokers and non-smokers are consistent with discounting hypothesis, and highly robust to an extensive array of control variables.
\end{abstract}


"I'd like to stop smoking. I have smoked for about 15 years. I was a dancer, and all dancers smoke, it's the most bizarre thing", Newark Star-Ledger, Jan. 1, '98.

\section{Introduction}

The title of our paper “Why Do Dancers Smoke?” suggests a paradox. Dancers place great importance on physical health, strength, and fitness; and yet, smoking leads to untoward health, loss of strength, and diminished fitness. We contend that the concept of time preference, or, in the economic parlance, of individual discount rates - i.e. the variation in individual valuations of present versus future consumption - resolves this apparent paradox. Both activities sacrifice some distant benefit for a more present-oriented gratification. Dancers are passionate, if not obsessed, with their work; but their careers are short with dim, if not non-existent, prospects of future earnings. Even more obvious is the fact that smokers sacrifice future health for an immediate source of pleasure. Hence the answer we consider is that dancers smoke because they are more present-oriented. ${ }^{1}$

The focus of the paper is on smoking and wage dynamics. Our main objective is to first empirically assess the correlation between smoking and wage growth over the life cycle, and second, to ask whether the estimated correlation between smoking and wage dynamics is consistent with the above time preference argument. Admittedly, our analysis of smoking and wage growth does not focus on dancers per se, and the intention of the opening paragraph is simply to motivate the hypothesis that individual discount rates may be a potentially important source of the observed differences in wage growth prospects among careers. Hence we need to address two key questions.

\footnotetext{
${ }^{1}$ Seminar participants never fail to point out the "real" reason why dancers smoke: weight control. Although this answer is not inconsistent with our claim that dancers have higher discount rates, among 120 plus professional dancers who smoke (based on a survey we conducted in New York City in 2001), a reason for smoking they least agree with is "weight control." Among the reasons they most agree with are "relaxation" and "enjoyment." In that survey, of over 300 professional dancers, about $40 \%$ were smokers, a rate substantially higher than the U.S. average for this age group. The Center for Disease Control reports that the average smoking rates for women and men age 18-34 (approximate age range in our sample) in 2000 were just shy of 25\% and 29\%, respectively (U.S. Department of Health and Human Services, 2002). Our sample is heavily biased toward women.
} 
First, what are the correlations between smoking and wage dynamics? Second, is smoking a reasonable proxy for an individual's discount rate?

Smokers in the U.S. earn substantially less than non-smokers. For example, Levine et. al. (1997), using the National Longitudinal Surveys of Youth (NLSY), find that smokers earn 11\% and 17\% less than non-smokers in 1984 and 1991, respectively. After controlling for a host of individual and family characteristics, this wage gap reduces to $4.2 \%$ and $6.9 \%{ }^{2}$ Using the same NLSY data, we find that the major source of this wage gap is the dramatic differences in wage growth rates between smokers and non-smokers. To preview our main findings: smokers have lower wages at the time they first enter the labor market compared to their non-smoking counterparts. And more strikingly, smokers also experience substantially lower wage growth over the first decade of their careers.

These differences in wage dynamics across smokers and non-smokers raise the interesting interpretive question about the possible direct and indirect causal mechanisms that may account for the observed correlations between smoking and wage dynamics. The evidence based on a detailed empirical analysis fails to reject the hypothesis that smokers are more likely to be present-oriented than their non-smoker counterparts, and hence our findings suggest that individual discount rates may play a significant role in career choice, investment in human capital, and, subsequently, differences in wage growth rates across individuals.

The idea that smoking is a proxy for discount rates is extensively documented in the economics literature (Fuchs, 1982). Empirical studies find correlations between smoking and various other behaviors related to future outcomes, including health status, educational attainment, earnings levels, use of seat belts, physical exercise, and brushing and flossing teeth (Hersch and

\footnotetext{
${ }^{2}$ See Leigh and Berger (1989) for an earlier study on the effect of smoking on wages.
} 
Viscusi 1990; Hersch 1996; Levine et. al. 1997; Hersch 2000; Viscusi and Hersch 2001). ${ }^{3}$ Our paper contributes to this literature by studying the role of time preference in predicting human capital investments, and thus, individual wage dynamics, a topic that has received little, if any, attention so far. In addition, our finding of a strong negative correlation between smoking and wage growth may be relevant to the literature that shows a correlation between health and income among adults (Smith, 1999). If individual discounting is causally linked to investments in health and investments in human capital (on the job) that enhance wage growth, then the positive correlation between health and income levels should become stronger with age since the benefits (and costs) of these investments (or lack of) materialize only later in life. ${ }^{4}$

One of the major challenges to any discounting hypothesis is the fact that individual discount rates are inherently unobservable. For example, in economics the discount rate is a conceptual device - an abstraction, if you will - that we use to aggregate benefits and costs that accrue over time. As such, the discount rate is not a fact but rather a plausible presumption that individuals are likely to differ in terms of their relative valuation of present versus future consumption. As a consequence, the purported link between smoking and discount rates can be challenged by a variety of alternative hypotheses that can also claim to account for the observed correlations between smoking and wage dynamics. Hence our empirical strategy is to explicitly test an exhaustive list of plausible but alternative explanations. Note that any such hypothesis must be on an omitted variable that is not only correlated with smoking but also more closely linked to

${ }^{3}$ Of course smoking is affected by a variety of factors in addition to time preference. For example, risk aversion, cigarette prices, parents' behavior, and even residential location (Gruber and Zinman, 2000), are likely determinants of smoking. To the extent that smoking better reflects these other factors vis-à-vis time preference, our assumption that smoking is a good proxy for discounting is indeed less sound, and thus, may lead to weaker empirical results.

${ }^{4}$ Smith (1999) focuses on the direct dual causation from health to wealth and from wealth to health. However, he alludes to a third possibility: “Or perhaps some unobserved factor makes some people both healthier and wealthier” (page 148). Our hypothesis is that individual discount rate is a likely contender of such an unobserved factor. 
workers' productivity and earnings. The obvious strategy, therefore, is to include a rich set of control variables - that represent the alternative hypotheses - and test for the importance and significance of the net correlations between smoking and wage dynamics.

Although we include a host of control variables in our regression analyses, this approach has two caveats that should be noted. First, some of these control variables are also likely to be correlated with time preference, and to the extent they are, the estimated net smoking effects should be interpreted as a lower bound of the effects of individual discounting. Second, since the discount rate is unobservable it is always possible to claim that the observed net correlations are due to yet "another" unobserved, or, even worse, unobservable individual characteristic. Of course, to qualify as a genuinely distinct hypothesis this omitted variable must be uncorrelated with discounting. These considerations and caveats guide the selection of control variables and our interpretation of the empirical findings.

The remainder of the paper is organized as follows. In Section 2 we discuss various theoretical linkages between wage dynamics, time preference, and smoking. In Section 3 we present our empirical results and discuss our findings. Section 4 concludes. A bibliography, data appendix, tables, and a figure are appended at the end.

\section{Smoking and Wage Dynamics: Conceptual Links}

In this section we consider various explanations for the observed correlations between smoking and wage dynamics. In Figure 1 we attempt to highlight some key factors and their inter-relationships to smoking and wage dynamics, including time preference and education. We begin with the discounting hypothesis and then continue to discuss various alternative hypotheses that might also explain the observed correlation between smoking and wage dynamics, including learning and education, among others. 
Discounting. Although our paper does not present a theory of time preference, in Figure 1 we list some possible determinants of individual time preference since some of these factors are likely to be selected as control variables. Apart from what might be unexplained sources of time preference, we think that background factors such as parental income and their educational attainments, family stability, and religious fervor, are likely determinants of time preference. ${ }^{5}$

The role of individual discount rates in predicting human capital investments, including onthe-job training, has been widely discussed in the labor economics literature (Becker 1975; Mincer 1974). ${ }^{6}$ For example, Haley (1973) explicitly states: “The rate of discount will be inversely related to the time spent specializing. This result makes eminently good sense. The higher the discount rate, the less value an individual places on future dollars relative to present dollars. The individual with the relatively higher discount rate will be less inclined to forego present income for investment purposes than would the individual with a relatively low discount rate. Therefore, if all other parameters are the same, the individual with the higher discount rate will stop specializing in the production of human capital sooner than the individual with a lower discount rate” (page 938).

This human capital investment framework is ideally suited to study the effects of time preference on various aspects of wage dynamics. If individuals with higher discount rates are less likely to invest in all forms of human capital then the ramifications for wages at the time of first

\footnotetext{
${ }^{5}$ Becker and Mulligan (1997) present a formal model of individual time preference where individual discount rates are viewed as an optimal choice variable given marginal costs and benefits of investment in activities that affect time preference.

${ }^{6}$ By focusing on heterogeneity of time preference among individuals we sidestep various interesting and controversial issues related to individual discounting. For example, Loewenstein (1992) challenges the implicit, if not standard, notion in microeconomic theory that individuals have a unique discount rate for all behaviors with future consequences. Although we speak of an individual discount rate, our assumption is much weaker than the assumption challenged by Loewenstein. We only need to assume that there is a high correlation of implied individual discount rates over a limited set of behaviors. Another recent debate centers on the appropriate specification of discounting. The issue is whether the standard exponential function should be replaced by a hyperbolic specification (e.g. see Laibson 1997). For a labor market application of hyperbolic discounting see Della Vigna and Paserman (2000). For a critical review of hyperbolic discounting, see Rubinstein (2003).
} 
entry into the labor market (first wage) and wage growth are straightforward. Individuals with high discount rates are likely to have lower and flatter wage profiles: lower because of smaller pre-labor market human capital investments and flatter because of smaller on-the-job human capital investments.

Theories of compensation based on considerations other than human capital are also likely to have similar predictions. For example, workers with high discount rates will find jobs with backload compensation - on account of say high monitoring costs (Lazear, 1981) or high turnover costs (Salop and Salop, 1976) - less attractive than their more future oriented counterparts. The general point is that dynamic theories of compensation imply that individuals with higher discount rates are less likely to self-select into jobs that weigh future wages more heavily than current wages. ${ }^{7}$

Since individual discount rates are unobservable, we study their effect on wage dynamics by assuming that smoking is a proxy for time preference. Hence our reduced form hypothesis is that smokers will have lower and flatter wage profiles. This presumed linkage between wage dynamics and smoking via time preference, however, must be moderated by consideration of other possible explanations for the observed correlations between smoking and wage dynamics. In the following we rehearse various alternative explanations with a view to empirical testing.

\footnotetext{
${ }^{7}$ Since individual discount rates are defined in terms of current versus future consumption and not in terms of current versus future incomes, we implicitly assume that workers face borrowing constraints against returns on investments in human capital. It should be noted, however, that even if the capital market is perfect, the returns on an investment in schooling, for example, depend on hours of work if schooling raises market productivity by a larger percentage than it raises nonmarket productivity. Individuals who are more future-oriented desire relatively more leisure at older ages. Therefore, they work more at younger ages and have a higher discounted marginal benefit on a given investment than persons who are more present oriented.
} 
Unobserved Learning. Heterogeneity of learning ability is another potential explanation of the observed correlation between smoking and wage dynamics. For example, more efficient (able) learners are likely to invest more in schooling as well as in other forms of human capital, including job training. As a consequence these efficient learners will have a higher first wage and a steeper wage profile. If they are also less likely to smoke because their higher learning ability leads them to better understand the negative effects of smoking, then it is possible that this unobserved dimension of ability could be the culprit behind the observed negative correlations between smoking and wage dynamics. $^{8}$ The fact that our regression results remain robust ${ }^{9}$ despite the inclusion of an extraordinarily rich set of control variables related to ability (see footnote 9) strongly suggests that unobserved ability is an unlikely explanation of the observed differences in wage dynamics across smokers and nonsmokers. ${ }^{10}$

Education. Although we have stressed the direct effects of time preference on smoking and occupational choice, ${ }^{11}$ we recognize other more subtle relationships between these variables. For example, consider the various inter relationships involving education. First, although educational levels (and other forms of human capital investments) are likely to be directly influenced by an

\footnotetext{
${ }^{8}$ Since the NLSY has information on a battery of ten ASVAB test scores (see data appendix for details), to claim that learning ability is unobserved seems somewhat tenuous. It stands to reason that at least some subset of these test scores will be correlated with such learning ability, and thus the inclusion of these test scores as independent variables in a wage growth regression should be a sufficient test of the learning hypothesis.

${ }^{9}$ While controlling for years of schooling reduced our estimated coefficients substantially, including additional controls had much smaller or no effect on our results.

${ }^{10}$ In another study we model wage dynamics as a function of individual discount rates and learning efficiency, and derive an empirical test to address whether smoking reflects discounting or learning ability. The empirical results overwhelmingly support the time preference hypothesis put forth in this paper (Munasinghe and Sicherman 2004).

${ }^{11}$ Wage growth is an important feature of occupations, and thus a key determinant of occupational choice. Although occupations differ on many dimensions, our focus in this paper is on the wage growth dimension only. As a consequence we view wage growth differences as reflecting occupational choice.
} 
individual's discount rate, there is also the possibility of reverse causality, namely, the effect of education on time preference. ${ }^{12}$ Second, education could also impact smoking behavior independent of time preference due to more efficient transmission of information about the hazards of smoking among the educated (Grossman 1972, 1975, Kenkel 1991). Third, the observed positive correlation between education and wage growth could be due to factors other than discounting such as complementarities between schooling and job training in production technology. Hence, including education as a control variable in a wage growth regression requires a more nuanced interpretation of our estimates of smoking coefficients. To the extent that education is correlated with smoking for reasons other than time preference, it should, of course, be included as a control variable. However, to the extent education also reflects time preference, the estimated coefficient on smoking (interpreted as a time preference effect) is likely to be biased downward.

Health. Health factors could be a direct explanation for the negative correlation between smoking and wage growth. Smokers are likely to be less healthy, and health could be a determining factor in investments in on-the-job training. ${ }^{13}$ We attempt to address this potentially important factor by explicitly considering the health status of our respondents in the NLSY. Although the negative correlation between smoking and wage growth persists despite the inclusion of health status as a

\footnotetext{
${ }^{12}$ Becker and Mulligan (1997) provide the following mechanism by which schooling can reduce discount rates: "Schooling focuses students' attention on the future. Schooling can communicate images of the situations and difficulties of adult life, which are the future of childhood and adolescence. In addition, through repeated practice at problem-solving, schooling helps children learn the art of scenario simulation” (pp. 735-736).

${ }^{13}$ The Becker-Mulligan framework suggests alternative interpretations of links between time preference and other outcomes such as health status. While Fuchs (1982) argues that differences in time preference explain differences in health related decisions and outcomes, Becker and Mulligan argue for reverse causality: People in better health are more likely to invest in activities that reduce their discount rate (because they expect to live longer). Of course exogenous events may also affect time preference. For example, Hersch (2000) finds that the presence of young children reduces smoking especially among women. Similarly, familiarity with life circumstances of older family members may lead to a more vivid and tangible picture of what one's own future beckons, and hence to a higher valuation of future outcomes.
} 
control variable, it indeed appears from our data that smokers are less healthy even in the short run.

Class. Another alternative explanation for the correlation between earnings growth and smoking could be based on the sociological concept of social class hierarchy. The argument is that social class, independent of time preference, is a determinant of both smoking and occupational choice, and thus, also of wage growth. For example, the correlation between wage growth and smoking could be due to the fact that blue-collar workers smoke more (because they are blue-collar workers) and because blue-collar jobs are typically low wage growth jobs. ${ }^{14}$ A counter argument is Banfield's thesis that social class itself is defined by time preference (Banfield 1970). To the extent that social class and time preference do not perfectly overlap, some of our control variables such as neighborhood income and parents education levels are likely to proxy social class. A related explanation could also be based on the idea that the culture of occupations may be more or less tolerant of smoking behavior. ${ }^{15}$ However, in our analysis this is unlikely to be a major cause of the correlations since we observe smoking behavior at a relatively early age. In Section 3.5 we provide additional evidence showing that smoking decisions are made at a relatively young age, based on a survey of several hundred College undergraduate students.

Borrowing Constraints. An argument based on borrowing constraints can also account for the correlations between smoking and wage dynamics. Suppose smokers come from relatively poor households that face credit and liquidity constraints. As a consequence they will be less able to make investments for the future. Because smoking is a proxy for family wealth and credit constraints, first wage and wage growth are likely to be negatively correlated with smoking. We

\footnotetext{
${ }^{14}$ Of course this explanation begs the question as to why blue collar workers smoke more than their white-collar counterparts.

${ }^{15}$ Although it is not obvious why jobs or occupations that are more tolerant of smoking are also low wage growth.
} 
attempt to address this issue by including parental education levels and measures of neighborhood income as control variables in our regression analyses.

Risk Taking. Some studies show a negative correlation between smoking and risk taking (e.g., Viscusi and Hersch, 2001, Barsky et al., 1997). However, as Shaw (1996) shows, “risk takers are rewarded with higher wage growth rates”. Therefore, the fact that we cannot directly control for risk aversion is likely to lead to a downward bias of our estimated smoking coefficient.

\section{Empirical Analysis}

\subsection{Data}

Our data from the National Longitudinal Surveys of Youth (NLSY) are ideally suited to study the role of smoking in predicting wage dynamics. The data contain information about smoking behavior of the respondents in their late teens and early twenties. The panel nature of the data and the fact that we observe the entire early work histories of the vast majority of our respondents allow us to directly correlate smoking behavior with individual earnings over the first decade or so of their careers. In addition, the NLSY data contain rich information on a variety of individual, family, geographic and work related characteristics. As a consequence, we are able to evaluate a large number of alternative hypotheses by including a rich array of control variables in our regression analyses. In the appendix we have a detailed description of the NLSY data.

\subsection{Wage growth measures}

We estimate a variety of wage growth functions within a simple least-squares framework. The basic regression equation is of the form:

$$
\Delta W_{i}=\alpha S_{i}+X_{i} \beta+\mu_{i}
$$

where $\Delta W$ is a measure of earnings or wage growth, $S$ is the smoking indicator, $X$ is a vector of 
individual and other characteristics, and $\mu$ is the error term for the $i^{\text {th }}$ individual. Given the young age of the NLSY sample, we compute these wage growth measures for approximately the first decade of labor market experience. Our construction of individual wage growth rates exploits the panel nature of the NLSY by running, for each individual in our sample, a simple OLS wage regression with time since first entering the labor market as the independent variable. We interpret the time coefficient as an estimate of the individual average wage growth rate and implement it as the dependent variable in our wage growth analyses. In the individual OLS regressions we specify the wage rate metric both as the real wage and as the log of real wage. ${ }^{16}$

We compute wage growth measures over long and short panels. In the long panel we use information over the entire observed career of each individual. ${ }^{17}$ However, in this panel labor market spells are correlated with age and schooling levels. This leads to biased estimates of wage growth rates since wage increases are more rapid in the early part of careers. For example, if we observe a shorter period of labor market experience for more educated groups we are likely to over estimate their wage growth rates. To address such concerns we construct wage growth measures from a panel that is restricted to the first six years of labor market experience. We also create a second short panel by further restricting it to only those with continuously valid wage observations in the first six years of their careers. ${ }^{18}$

\subsection{Descriptive statistics}

${ }^{16}$ Standard wage equations, of course, only use the log specification. The reason for this practice is the universal implementation of Mincer's human capital earnings function. In the context of our paper, where what matters is the perception of wage increases, it is not evident a priori which measure of wage growth is more relevant. Therefore, we present evidence using both measures. In a previous version of the paper we also used nominal wages and its log counterpart and duplicated the same qualitative results.

${ }^{17}$ Although individuals are surveyed from 1979 to 1994 in the NLSY, they “enter” our sample only when they first enter the labor market.

${ }^{18}$ If more future oriented individuals are more likely to work continuously, such a constraint might bias the sample. 
Table 1 presents smoking rates (reported in 1984) for a select group of occupations. In our entire sample 38\% were classified as smokers in $1984 .{ }^{19}$ The variation in this gross smoking rate is quite dramatic with "Maids and Housemen” at the high end with a smoking rate of 62\%, and "Teachers in Elementary Schools” at the low end with less than $10 \%$. These rates are comparable to estimates found in other studies. ${ }^{20}$

Table 2 presents some descriptive statistics for smokers and non-smokers. These gross mean characteristics are strikingly different. For example, educational attainment is substantially higher among non-smokers. ${ }^{21}$ Non-smokers, on average, have over one and a quarter more years of completed schooling, are much more likely to have a high school diploma, and score about 10 points higher on the Armed Forces Qualifying Tests (AFQT). The differences in labor market outcomes are even more dramatic. Smokers enter the labor market earlier than non-smokers due to their lower level of schooling, thus their higher level of potential market experience. However, non-smokers have more "net” labor market experience, lower turnover rates, and earn more than smokers $^{22}$. Not surprisingly, a relatively smaller percent of non-smokers report health as a limiting factor to the amount and kind of work they could do. ${ }^{23}$

\footnotetext{
${ }^{19}$ We define a smoker as someone who smokes at least one cigarette per day on average. This definition is more or less comparable to the definition of "current smoker" used by the US Center for Disease Control. See the data appendix for further details. As a comparison, Evans and Montgomery (1994) report 30\% for the 1987 National Medical Expenditure Survey (NMES), and 33\% for the 1987 National Health Interview Survey (NHIS). Levine, Gustafson and Velenchik (1997), also using the NLSY, report smoking rates of 37\% in 1984 and 29\% 1991.
}

${ }^{20}$ Although the detailed rankings of occupations by smoking has varied over the years (Nelson et.al. 1994), they are broadly similar to ours, where blue collar workers are at the top, and white collar workers are at the bottom, where teachers and sales representative have the lowest smoking rates (Bang and Kim, 2001)

${ }^{21}$ This is a well-documented finding (see Sander 1995).

22 The gap between "potential experience” (age-schooling-6) and “net” experience (actual years of employment) also reflects the higher turnover and unemployment rates of smokers.

${ }^{23}$ It is possible that individuals having health problems will select into jobs where their health problems do not limit their work, thus resulting in an underestimation of health problems due to 
The gross hourly pay is substantially lower for smokers compared to non-smokers. On average, the non-smoker wage premium is over $15 \%$. The differences in first wage and wage growth rates provide further insight into the overall wage disparity between smokers and nonsmokers. The mean first wage is lower for smokers, but this difference (7\%) is not as substantial as the difference in overall wages. However, the substantial difference in the increases in hourly wages (.34 versus .21) represents a huge wage growth premium of over $60 \%$ between smokers and non-smokers, and thus suggests that wage growth differentials are largely responsible for the welldocumented fact that smokers earn less than non-smokers. ${ }^{24}$

\subsection{Regressions results}

\subsubsection{First wage and smoking}

Table 3 reports OLS estimates from regressions where the dependent variable is the individual's reported wage at the time the individual first enters the labor market (first wage). The numbers in the table show only the coefficients of the smoking variable under various model specifications. First wages are about forty cents lower for smokers. This represents a $4.7 \%$ wage gap between smokers and non-smokers. This wage gap reduces by half after controlling for a rich set of

smoking. We hope that the use of the word "could” in the survey instrument reduces such a problem. (See data appendix for the exact wording of the survey instrument.) For additional evidence on the health limitations of smoking on the job see Leigh (1985 and 1986).

${ }^{24}$ If smoking is a proxy for discounting then our measure of wage growth may in fact underestimate the "effective” wage growth rate for non-smokers. Since non-smokers are more likely to have a College degree and thus have considerably higher debt, their wages during the early part of careers will overstate their disposable income. Hence the "effective” wage growth differential between non-smokers and smokers is likely to be even higher than what is suggested by our measured wage growth differences. Similar considerations suggest that the "effective" first wage differences between non-smokers and smokers will be smaller than the gross differences presented in Table 2. These considerations, however, are unlikely to lead to any first order bias of our regression coefficients since we control for completed years of schooling. 
individual and family characteristics. ${ }^{25}$ As we argued earlier this estimated difference in first wages

is consistent with the time preference hypothesis that smokers, because they are more present

oriented, are likely to invest less in both observed and unobserved pre-market human capital, and thus experience lower first wages. We now turn to our analyses of the correlations between smoking and wage growth rates.

\subsubsection{Wage growth and smoking}

Tables 4 through 6 present regression results on the partial correlation between wage growth and smoking. Although we report only the coefficient on smoking, the numerous estimates we present reflect different data samples, wage metrics, and the addition of more control variables. The two columns in each table show estimates from regressions using two different wage growth metrics based on dollar wages and log wages, respectively. The numbers going down the rows are smoking coefficients from regression specifications that cumulatively add more control variables. Note that in our first row the only variable, in addition to smoking, is the first wage. ${ }^{26}$ Finally, Tables 4 through 6 show estimates based on the long, short and continuously short panels, respectively. In Appendix Table 1 we report the full regression results for two of the models presented in Table 4.

The striking finding across the various wage growth metrics and model specifications is the

\footnotetext{
${ }^{25}$ These estimated differences in first wages are likely to underestimate the true differences in levels of pre-labor market human capital between non-smokers and smokers if non-smokers are taking relatively higher initial wage reductions due to higher on-the-job investments.

${ }^{26}$ The reason for including first wage in the regressions is because equilibrium considerations of wage dynamics imply a trade-off between first wage and wage growth. Equilibrium in the labor market implies that jobs with different wage growth rates will have comparable value. As a consequence, when a worker accepts a job she must pay for the option of high wage growth by accepting a lower initial wage. Hence these dynamic models of compensation imply a negative correlation between first wage and wage growth, holding all other factors constant including the discount rate (see, for example, Munasinghe, 2000). Although we do not report the coefficient estimates of first wage here, across all our model specifications the estimated coefficient of first wage is negative as predicted (see Appendix Table 1). In addition, first wage is likely to be an indicator for unobserved heterogeneity in skills, thus providing an additional control for heterogeneity across smokers and non-smokers.
} 
negative and significant correlation between smoking and wage growth. This result is robust to the inclusion of many control variables. The negative correlation between smoking and wage growth increases somewhat after controlling for age, race, and gender. Unsurprisingly, including completed years of schooling in wage growth regressions reduces this negative correlation substantially. Note, however, that the net effect of smoking still remains significant across all specifications. Including AFQT scores as a proxy for unobserved characteristics such as intelligence, schooling quality, and skills learned at home, ${ }^{27}$ leads to a further reduction of the negative effect of smoking. However, the negative smoking coefficient remains large and significant. $^{28}$

In Section 2.2 we discussed a variety of alternative explanations and the possible inclusion of certain control variables as a means of evaluating the predictive power of these hypotheses. Our finding that the inclusion of schooling reduces the smoking coefficient substantially raises an interpretive question. To the extent that schooling and smoking are correlated for reasons quite apart from time preference, the reduced impact of smoking on wage growth should be interpreted as an unbiased estimate of time preference. However, to the extent that the correlation between schooling and smoking is due to time preference, this estimated coefficient should be interpreted as a lower bound of the time preference effect. Similar considerations apply to the inclusion of AFQT scores as a control variable.

We also identified a variety of other potentially important control variables. The hypothesis that budget constraints of poor households limit their access to human capital investments coupled with the fact that the poor are more likely to smoke suggested the inclusion of household income as

\footnotetext{
${ }^{27}$ While some studies used the AFQT scores as a proxy for intelligence, others have argued that these scores reflect mainly quality of schooling and skills learned during childhood.

${ }^{28}$ The AFQT score is a weighted mean of four test scores from the ten Armed Services Vocational Aptitude Battery (ASVAB) tests administered to the NLSY respondents in 1980 (See the data appendix for details). Replacing the AFQT score with the ten separate scores did not affect our results.
} 
a test of this hypothesis. Since we do not have income information of parents of NLSY

respondents, we constructed a “neighborhood” income variable using census data from 1980 on the basis of race and education level of parents. Although this average neighborhood income variable is positively correlated with wage growth, our smoking coefficients remain highly robust. ${ }^{29}$ In fact the inclusion of a host of other variables (in the last row of each table), such as health status, religious affiliation and frequency of attendance of religious service, barely changes the coefficient estimate of smoking.

In summary: the negative smoking coefficient reduces substantially when human capital variables are included (education and AFQT scores); it is highly robust to a whole host of additional control variables; and more importantly, it remains significant across all model specifications.

Next we address the question of magnitude of these wage growth differences between smokers and non-smokers. Table 7 shows the wage growth differentials for the three data samples we use in our regression analyses. Each number represents the mean wage growth difference between non-smokers and smokers as a percentage of the mean wage growth of smokers. The numerator of the "gross" columns is based on sample mean differentials, and the numerator of the "net” columns is based on the smoking coefficient from the wage growth regression with the most extensive controls, including first wage, completed years of schooling and AFQT scores. These results are presented for two wage growth metrics - real wage growth in dollar and percentage terms, respectively.

The striking result is the huge difference in the mean wage growth rates between nonsmokers and smokers. Across the different sample restrictions and wage growth metrics, this wage growth differential varies from a low of $31 \%$ to a high of $65 \%$. Put simply, the mean annual wage

\footnotetext{
${ }^{29}$ We also experimented with including an interaction between smoking and neighborhood income to test whether smoking may have an even more negative effect on wage growth among poorer households. Our estimates of this interaction effect were by and large insignificant. Perhaps, a more refined measure of household wealth may have lead to a different result.
} 
growth of non-smokers is about $50 \%$ higher than it is for smokers. As we predicted earlier in our discussion, this differential is substantially reduced when the schooling effects are netted out. But notice that the net effect of non-smoking on wage growth still remains sizeable - from a low estimate of $15 \%$ to a high estimate of almost $40 \%$. Of course, the real impact of discount rates on wage growth is likely to be higher than this net estimate via smoking since schooling (as well as other variables like AFQT scores) is also likely to be correlated with individual discount rates. So these "net" effects should be interpreted as low bound estimates of the effect of discounting on wage growth.

\subsection{Survey of College Students}

We conclude our empirical analysis by presenting some evidence on smoking and choice of college majors. Our working hypothesis is that the correlation between occupational choice (i.e., investment in human capital) and smoking does not reflect any causal relationship. Both decisions are affected by the individual's rate of time preference. An alternative hypothesis is that there is a causal relationship from occupational choice to smoking. For some reasons, working in a given occupation affects the likelihood of smoking. This potential problem is partially taken care of by the fact that the smoking information in our data is collected at a relatively young age, which is, in most cases, prior to entry into the labor market. In this section we report smoking rates across college majors. The results further support the hypothesis that smoking decisions are made prior to entry into the labor market and probably even prior to entry to college.

We administered over 400 surveys to Barnard and Columbia College undergraduates in 1999. The survey contained a series of questions about smoking and other behaviors related to future outcomes. We also collected information on gender, college major, ethnicity, religious affiliation, and family background. Students from about 30 majors were sampled. However, in our analysis we only use the top 10 majors because of sample size considerations. In Table 8 we 
present smoking rates by major. The first column of Table 8 lists the top ten majors by sample size. The order of majors from top to bottom is ranked from the highest smoking rate to the lowest. The two majors with the highest smoking rates are Dance and English, and with the lowest smoking rates are Engineering and Psychology. Defining smokers as those smoking at least five cigarettes per day ("Smoker 2") leads to a single switch between the top five and the bottom five majors History majors switch to the low end from the high end, and Political Science majors switch from low to high. What is striking in this table is the large variation in smoking rates by major - from $67 \%$ of Dance majors to just $17 \%$ of Psychology majors. To address the possible objection that this variation might be explained by the "culture" of departments or majors, we computed the percent of current smokers that started smoking prior to coming to College. This information is presented in the last column of Table 8 under the label "Prior Smoker." The numbers do not show a strong pattern, except that a higher fraction of smokers in the Dance and English departments appear to have also started smoking prior to coming to College.

Although it might be tempting to assert that Dance and English majors have poorer earnings prospects, we make no attempt here to present evidence about differences in expected future earnings across college majors. This evidence, no doubt preliminary and tangential, should raise some caution about the "culture" of occupation or profession as an important cause of smoking.

\section{Conclusion}

We find that smokers have lower and flatter wage profiles compared to non-smokers. This finding is robust to a variety of wage growth measures and inclusion of a host of control variables. The results are consistent with the hypothesis that smoking is a proxy for time preference, especially given the use of an extraordinary rich set of controls for heterogeneity in ability across individuals. Therefore, our findings highlight the importance of discounting in individuals' decision making in the labor market as well as in health related decisions. 
Public policy consensus highlights the importance of early education and intervention. Our findings suggest that such interventions should focus on influencing a child's time preference. The factors and mechanisms that determine time preference should therefore be a high priority for research and public policy discussion. 


\section{References}

Bang, K. M., and Kim, J. H. Prevalence of Cigarette Smoking by Occupation and Industry in the United States. American Journal of Industrial Medicine, September 2001, 233-239.

Banfield, E. C. The Unheavenly City: The Nature and Future of Our Urban Crisis. Boston, MA: Little, Brown and Company, 1970.

Barsky, R., Juster, F. S., Kimball, M. S., and Shapiro, M.D. Preference Parameters and Behavioral Heterogeneity: An Experimental Approach in the Health and Retirement Study. The Quarterly Journal of Economics, May 1997, 537-580.

Becker, G. S., and Mulligan, C. The Endogenous Determination of Time Preference. Quarterly Journal of Economics, August 1997, 729-758.

Becker, G. Human Capital, 2nd Edition, Chicago, IL: University of Chicago Press, 1975.

Della Vigna, S., and .Paserman, D. Job Search and Hyperbolic Discounting. Harvard University working paper, January, 2000.

Evans, W. N., and Montgomery, E. Education and Health: Where There's Smoke There's an Instrument. NBER working paper No. 4949, December 1994.

Fuchs, V. R. Time Preference and Health: An Exploratory Study. In V.R. Fuchs (Ed.) Economic Aspects of Health, Chicago, IL: University of Chicago Press, 1982, 93-120

Grossman, M. The Demand for Health. New York, NY: National Bureau of Economic Research, 1972.

Grossman, M. The Correlation between Health and Smoking. In Terleckyj, N.E. (Ed.) Household Production and Consumption, New York, NY: National Bureau of Economic Research, 1975, 147-211.

Gruber, J. and Zinman, J. Youth Smoking in the U.S.: Evidence and Implications. NBER Working paper No. 7780, July 2000.

Haley, W. J. Human Capital: The Choice between Investment and Income. The American Economic Review, December 1973, 929-944.

Hersch, J. Smoking, Seat Belts, and Other Risky Consumer Decisions: Differences by Gender and Race. Managerial and Decision Economics, September 1996, 471-481.

Hersch, J. Gender, Income Levels, and the Demand for Cigarettes. Journal of Risk and Uncertainty, November 2000, 263-282.

Hersch, J., and .Viscusi, W. K. Cigarette Smoking, Seatbelt Use, and Differences in Wage-Risk Tradeoffs. The Journal of Human Resources, Spring 1990, 202-227.

Kenkel, D. S. Health Behavior, Health Knowledge, and Schooling. Journal Political Economics, April 1991, 287-305. 
Laibson, D. Golden Eggs and Hyperbolic discounting. The Quarterly Journal of Economics, May 1997, .443-477.

Lazear, E. P. Agency, Earnings Profile, Productivity, and Hours Restrictions. American Economic Review, September 1981, 606-20.

Leigh, J. P. An empirical analysis of self-reported, work-limiting disability. Med Care. April 1985, 310-319.

Leigh, J. P. Correlates of Absence From Work due to Illness. Human Relations, January 1986, 81100.

Leigh, J. P. and Berger, M. C. Effects of Smoking and Being Overweight on Current Earnings. American Journal of Preventive Medicine, Jan.-Feb. 1989, 8-14.

Levine, P. B., Gustafson, T. A., and Velenchik, A. D. More Bad News for Smokers? The Effects of Cigarette Smoking on Wages. Industrial and Labor Relations Review, April 1997, 493-509.

Loewenstein, G. The Fall and Rise of Psychological Explanation in the Economics of Intertemporal Choice. In G. Loewenstein and J. Elster (Eds.), Choice over time. New York, NY: Russell Sage, 1992, 3-34.

Mincer, J. Schooling, Experience, and Earnings. New York, NY: Gregg Revivals, 1993; Original publication 1974.

Munasinghe, L. Wage Growth and the Theory of Turnover. Journal of Labor Economics, April 2000, 204-220.

Munasinghe, L., and Sicherman, N. Wage Dynamics and Unobserved Heterogeneity: Time Preference or Ability? Working Paper, Columbia University, 2004.

Nelson, D. E., Emont, S. L., Brackbill, R. M., Cameron, L. L., Peddicord, J., and Fiore, M. C. Cigarette smoking prevalence by occupation in the United States. A comparison between 1978 to 1980 and 1987 to 1990. J. Occup. Med., May 1994, 516-525.

Rubinstein, A. “Economics and Psychology?” The Case of Hyperbolic Discounting. International Economic Review, November 2003, 1207-1216.

Salop, J. and Salop, S. Self-Selection and Turnover in the Labor Market. Quarterly Journal of Economics, November 1976, 619-627.

Sander, W. Schooling and Smoking. Economics of Education Review, March 1995, 23-33.

Shaw, K L. An Empirical Analysis of Risk Aversion and Income Growth. Journal of Labor Economics, October 1996, 626-653.

Smith, J. P. Healthy Bodies and Thick Wallets: The Dual Relation Between Health and Economic Status. Journal of Economic Perspectives, Spring 1999, 145-166. 
Viscusi, W. K., and Hersch, J. Cigarette Smokers as Job Risk Takers. The Review of Economics and Statistics, May 2001, 269-280.

U.S. Department of Health and Human Services. Health, United States, 2002, with Chart book on Trends in the Health of Americans. Hyattsville, MD: Center for Disease Control and Prevention, National Center for Health Statistics Division of Data Services, September 2002. 


\section{Data Appendix: National Longitudinal Surveys of Youth, 1979-94}

Our data is from the NLSY. This is a panel of 12,686 youth, aged 14-21 in 1978, and sampled continuously since 1979. Our sample includes data up to 1994. We include individuals in our sample when they first report that their "main activity" is "working." Therefore, our "First Wage” variable is recorded accordingly. The key variable of our analysis is whether, in 1984, respondents answered affirmatively to whether they smoked or not. We classify a smoker (in 1984) as a person who at least smoked one cigarette per day on average. Out of 12,584 who responded, 38.8\% were classified as smokers. Similar, but not exact, questions were also asked in 1992. A smoker was classified as someone who “smokes daily” (as opposed to “occasionally” or "not at all”). Of the 8,341 who responded in 1992, 28.92\% were classified as smokers. We utilized only the 1984 smoking questions for the following reasons: By 1992 the number of individuals that answered the smoking survey dropped dramatically, due to sample attrition. Only 7,822 individuals answered the 1992 survey and had valid wage growth measures. More important, the sample attrition was not random. Individuals who smoked in 1984 were more likely to drop out, and even worse, those with lower wage growth were substantially more likely to drop out.

Our principal dependent variable is a wage growth measure for each individual constructed over the first several years in the labor market. We construct a wage growth coefficient for each individual by estimating a wage regression as a function of time only. This estimated coefficient is our measure of individual wage growth rates. For wages we use two measures of hourly payments, real wages (in 1987 dollars) and their natural logarithm. In an earlier version of the paper we also used nominal wages. Since none of our results was affected by the use of nominal wages, we limit the analysis here to real wages. We consider wage reports to be valid only if nominal pay is between \$2 and \$200. Given the construction of our wage growth measure, a minimum of two valid observations per individual is required in order to be included in the sample.

We construct two versions of this estimate: (1) using the longest panel of data for each 
individual, and (2) using only the first 6 years in the labor market - counting the first 6 surveys/years since entering the labor market. This allows for less than 6 observations if individuals leave missing values in some years.

Below we discuss the construction of several key variables used in the regressions:

“Health” - Respondents in the NLSY were asked, in each survey, the following two questions: (1) "hltamt” - whether health limited the amount of work you could do since last survey (“(are you/would you be) limited in the kind of work you (could) do on a job for pay because of your health?”), and (2) “hltknd” - whether health limited the kind of work you could do since last survey (“(are you/would you be) limited in the amount of work you (could) do because of your health?”). Using the answer to these two questions we constructed several other additional health measures:

(1) “evera” - if a person ever reported hltamt=1,

(2) “everk” - if a person ever reported hltknd=1,

(3) “mhlta” - \% of times reported hltamt=1, and

(4) “mhltk" - \% of times reported hltknd=1.

We experimented with all measures but report regressions' result using “mhltk” only. None of the results was affected by using any of the other alternative measures of health.

Schooling: We use the respondents report on "highest grade completed" to construct six schooling dummies: 8 years or less, 9-11 years, 12 years, $12-15$ years, 16 years, and $17+$ years. We report only the results using the dummy variables. Replacing the schooling dummies with the continuous measure didn’t affect our results.

AFQT Scores: During the summer and fall of 1980, NLSY79 respondents participated in an effort of the U.S. Departments of Defense and Military Services to update the norms of the Armed Services Vocational Aptitude Battery (ASVAB). The Department of Defense and Congress, after questioning the appropriateness of using the World War II reference population as the primary basis for interpreting the enlistment test scores of contemporary recruits, decided in 1979 to 
conduct this new study. NLSY79 respondents were selected since they comprised a pre-existing nationally representative sample of young people born during the period 1957 through 1964 . This testing, which came to be referred to as the "Profile of American Youth," was conducted by NORC (National Organization for Research at the University of Chicago) representatives according to standard $A S V A B$ procedure guidelines; respondents were paid $\$ 50$ for their participation. Groups of five to ten persons were tested at more than 400 test sites, including hotels, community centers, and libraries throughout the United States and abroad. A total of 11,914 civilian and military NLSY79 respondents (or 94 percent of the 1979 sample) completed this test: 5,766 or 94.4 percent of the cross- sectional sample, 4,990 or 94.2 percent of the supplemental sample, and 1,158 or 90.5 percent of the military sample.

The $A S V A B$ consists of a battery of 10 tests that measure knowledge and skill in the following areas: (1) general science; (2) arithmetic reasoning; (3) word knowledge; (4) paragraph comprehension; (5) numerical operations; (6) coding speed; (7) auto and shop information; (8) mathematics knowledge; (9) mechanical comprehension; and (10) electronics information. A composite score derived from select sections of the battery can be used to construct an approximate and unofficial Armed Forces Qualifications Test score (AFQT) for each youth. The AFQT is a general measure of trainability and a primary criterion of enlistment eligibility for the Armed Forces. The creation of this percentile score, called AFQT89, involves: (1) computing a verbal composite score by summing word knowledge and paragraph comprehension raw scores; (2) converting subtest raw scores for verbal, math knowledge, and arithmetic reasoning; (3) multiplying the verbal standard score by two; (4) summing the standard scores for verbal, math knowledge, and arithmetic reasoning; and (5) converting the summed standard score to a percentile.

Religion: We use two indicators for religious affiliation and frequency of attending religious services: (1) dummy variables indicating whether the person was raised Protestant, 
Baptist, Episcopalian, Lutheran, Methodist, Presbyterian, Roman Catholic, or Jewish. (2) The frequency in which respondents attended religious services (never, several times a year, about once a month, three times a month, about once a week, or more than once a week). In the regressions' results reported in the paper we include both measures: religious affiliation and frequency of attendance.

"Neighborhood Income”: This variable was constructed using the 1980 census of population and later matched to the NLSY sample. It was calculated to describe the expected value of a person’s neighborhood per capita income, given their race (white, black, or Hispanic), education level (less than 8 years, 9-11 years, 12-15 years, or 16+ years), and the county they live in, using data from the 1980 Census. Neighborhoods are defined as block groups in the 1980 Census, so each block group’s per capita income was calculated by dividing aggregate household income for the block group by the total number of persons living in that block group. (Both of these were variables given to us by the census.) Since the 1980 Census does not include Hispanic as one of their race categories, but rather as an ethnic category separate of race (Hispanic persons were placed into one of five race categories: white, black, Asian, Native American or other.), we needed to approximate the number of Hispanics, non-Hispanic whites and non-Hispanic blacks living in each block group. We did this by generating a beta for each race, which would represent the percent of Hispanic persons that are of that race, and multiplying it by the number of Hispanic persons living in the block group. This would approximate the number of Hispanic persons that were recorded as belonging to each race, so that these categories could be amended. (This process was done for each block group and for each education level. It was repeated several times, replacing the betas, for precision.) The outcomes of this process were numbers for Hispanic, nonHispanic white, and non-Hispanic black persons in each education level for each block group. “Neighborhood Income” was then found by creating the expected value of a person of race X and education level Y for each county. 
Appendix Table 1

Wage Growth Regression

OLS estimation results (standard errors in parentheses). Sample: Long Panel

\begin{tabular}{|c|c|c|}
\hline & \multicolumn{2}{|c|}{ Wage growth measures are based on } \\
\hline & (i) Real Wage & (ii) Log of real wage \\
\hline \multirow[t]{2}{*}{ Smoker } & -.052 & -.0048 \\
\hline & $(.018)$ & $(.0019)$ \\
\hline \multirow[t]{2}{*}{ First Real Wage } & -.084 & -.0818 \\
\hline & $(.002)$ & $(.0026)$ \\
\hline \multirow[t]{2}{*}{ Sex (if male) } & .197 & .0220 \\
\hline & $(.016)$ & $(.0018)$ \\
\hline \multirow[t]{2}{*}{ Race (if non-white) } & .030 & -.0001 \\
\hline & $(.022)$ & $(.002)$ \\
\hline \multirow[t]{2}{*}{ Age in 1984} & -.008 & -.0015 \\
\hline & $(.003)$ & $(.0004)$ \\
\hline \multirow[t]{2}{*}{ Schooling: 9-11 years } & -.024 & .0028 \\
\hline & $(.052)$ & $(.0055)$ \\
\hline \multirow[t]{2}{*}{12 years } & .007 & .0105 \\
\hline & $(.050)$ & $(.0054)$ \\
\hline \multirow[t]{2}{*}{$12-15$ years } & .110 & .0226 \\
\hline & $(.053)$ & $(.0057)$ \\
\hline \multirow[t]{2}{*}{16 years } & .352 & .0438 \\
\hline & $(.058)$ & $(.0062)$ \\
\hline \multirow[t]{2}{*}{$17+$ years } & .418 & .0451 \\
\hline & $(.062)$ & $(.0067)$ \\
\hline \multirow[t]{2}{*}{ AFQT scores } & .003 & .0003 \\
\hline & $(.0004)$ & $(.00004)$ \\
\hline \multirow[t]{2}{*}{ Health problems } & -.276 & -.0358 \\
\hline & $(.074)$ & $(.0080)$ \\
\hline \multirow[t]{2}{*}{ Neighborhood income } & .00003 & .000003 \\
\hline & $(.000006)$ & $(.0000006)$ \\
\hline \multicolumn{3}{|c|}{ Religious affiliation (excluded: Presbyterian) } \\
\hline \multirow[t]{2}{*}{ Raised Protestant } & -.021 & .0006 \\
\hline & $(.048)$ & $(.0052)$ \\
\hline \multirow[t]{2}{*}{ Raised Baptist } & -.044 & -.0034 \\
\hline & $(.035)$ & $(.0038)$ \\
\hline \multirow[t]{2}{*}{ Raised Episcopalian } & -.039 & -.0016 \\
\hline & $(.071)$ & $(.0076)$ \\
\hline \multirow[t]{2}{*}{ Raised Lutheran } & -.021 & -.0027 \\
\hline & $(.046)$ & $(.0050)$ \\
\hline \multirow[t]{2}{*}{ Raised Methodist } & -.036 & -.0041 \\
\hline & $(.042)$ & $(.0045)$ \\
\hline \multirow[t]{2}{*}{ Raised Roman Catholic } & .007 & .0008 \\
\hline & $(.003)$ & $(.0037)$ \\
\hline \multirow[t]{2}{*}{ Raised Jewish } & .187 & -.0017 \\
\hline & $(.090)$ & $(.0097)$ \\
\hline \multirow[t]{2}{*}{ Raised other } & -.043 & -.0053 \\
\hline & $(.040)$ & $(.0043)$ \\
\hline
\end{tabular}

Continue on next page. 
Appendix Table 1 - Continue

\begin{tabular}{|l|l|l|}
\hline & \multicolumn{2}{|c|}{ Wage growth measures are based on } \\
\hline & (i) Real Wage & (ii) Log of real wage \\
\hline Frequency of attending services (excluded: “never”) & & \\
\hline Several times a year & .040 & .0007 \\
\hline & $(.024)$ & $(.0026)$ \\
\hline About once a month & .022 & .0020 \\
\hline & $(.033)$ & $(.0035)$ \\
\hline Three times a month & -.014 & -.0046 \\
\hline & $(.030)$ & $(.0033)$ \\
\hline About once a week & .017 & -.0018 \\
\hline & $(.026)$ & $(.0029)$ \\
\hline More than once a week & -.004 & -.0037 \\
\hline & $(.033)$ & $(.0036)$ \\
\hline Constant term & .4118 & .1475 \\
\hline & $(.111)$ & $(.012)$ \\
\hline $\mathrm{R}^{2}$ & .19 & .14 \\
\hline Number of observations & 9396 & 9396 \\
\hline
\end{tabular}


Table 1

\section{Smoking Rates by Select Occupations ${ }^{1}$ NLSY 1984}

Occupation

All

Maids and Housemen

Roofers

Kitchen workers

Waiters

Heavy truck drivers

Laborers and Construction

Carpenters

Janitors and Cleaners

Housekeepers and Butlers

Truck drivers (light)

Teachers (n.e.c.) ${ }^{2}$

Cashiers

Sales workers, other commodities

Secretaries

Athletes

Computer Programmers

Teachers, elementary schools
Smoking Rate

.376

.621

.600

.566

.554

.509

.476

.451

.413

.386

.365

.349

.348

.325

.283

.226

.208

.094

\section{Observations}

9,501

66

40

53

233

106

504

82

305

171

126

43

391

351

297

31

101

53

${ }^{1}$ Occupations are randomly selected across the spectrum of smoking rates with the exception that we omit occupations with very low sample sizes.

${ }^{2}$ Not elsewhere classified. 
Table 2

\section{Descriptive Statistics across Smokers and Non-smokers NLSY 1979-1994}

\begin{tabular}{|c|c|c|}
\hline & Non-Smokers & Smoke \\
\hline Age (in 1984) & 23.49 & 23.66 \\
\hline Non white & .43 & .37 \\
\hline Sex (\% males) & .49 & .54 \\
\hline Married & .44 & .38 \\
\hline Schooling & 13.3 & 11.9 \\
\hline High School Diploma & .86 & .66 \\
\hline Afqt89 & 45.3 & 34.7 \\
\hline Father's schooling & 9.7 & 9.1 \\
\hline Mother's schooling & 10.4 & 9.9 \\
\hline Health limit kind of work & .035 & .045 \\
\hline Net years of experience (in 1994)* & 11.5 & 10.4 \\
\hline Potential years of experience (in 1994)* & 14.1 & 15.8 \\
\hline First wage (real) & 5.91 & 5.55 \\
\hline First wage (nominal) & 4.77 & 4.36 \\
\hline Hourly (nominal) pay (79-94) & 13.29 & 11.54 \\
\hline Changed employer since last interview (79-94) & .354 & .431 \\
\hline Quit job (79-94) & .245 & .288 \\
\hline Was laid-off (79-94) & .068 & .086 \\
\hline Was fired (79-94) & .016 & .031 \\
\hline Increases in hourly wages (nominal) & .67 & .49 \\
\hline Increases in hourly wages (in 1987 dollars) & .34 & .21 \\
\hline First six years in the labor market & .39 & .23 \\
\hline First six years, no missing observations & .44 & .32 \\
\hline Increases in log hourly wages (in 1987 dollars) & .037 & .025 \\
\hline First six years in the labor market & .050 & .031 \\
\hline First six years, no missing observations & .057 & .044 \\
\hline
\end{tabular}

* "Net" refers to actual years of experience, while "potential" experience is calculated as (ageschooling-6).

Number of observation varies across variables. For fixed individual characteristics the number is about 6700, and for means taken over the whole 79-94 period, the number is about 50,000 valid observations.

All mean differences are significantly different from zero, using 99\% confidence level (the t-test was performed assuming equal variance). 


\section{Table 3}

\section{First Wage Regressions OLS Smoking Coefficients Standard Errors are in parentheses Sample: Long panel ${ }^{1}$}

$\begin{array}{lll} & \text { Real Wage } & \begin{array}{l}\text { Log Real } \\ \text { Wage }\end{array} \\ \text { No Controls } & -0.404 & -0.047 \\ \text { Limited Controls }^{2} & (0.081) & (0.005) \\ & -0.209 & -0.022 \\ \text { Full Controls }^{3} & (0.084) & (0.008) \\ & -0.213 & -0.024 \\ & (0.084) & (0.008)\end{array}$

Notes

${ }^{1}$ Includes the first wage of our long panel sample.

${ }^{2}$ Limited Controls include age, race, sex, schooling, and AFQT scores.

${ }^{3}$ Full Controls include in addition to the above also health status, measure of average neighborhood income, and religious affiliation. See Notes to Table 4 and the Data Appendix for more details. 


\section{Table 4}

\section{Wage Growth Regressions \\ OLS Smoking Coefficients \\ (Standard Errors in Parentheses) \\ Sample: Long panel ${ }^{1}$}

Wage growth measures based on

$\begin{array}{ll}\text { (i) Real wage } & \text { (ii) Log of real wage }\end{array}$

Cumulative Controls ${ }^{2}$

1. First Real Wage

$-.158$

$-.0152$

(.017)

(.0018)

2. Sex, Race \& Age

$-.179$

$-.0173$

(.017)

(.0018)

3. Schooling

$-.059$

$-.0053$

(.018)

(.0019)

4. AFQT

$-.048$

$-.0043$

$(.018)$

(.0019)

5. Health, Neighborhood

$-.052$

$-.0048$

Income, Religion

(.018)

(.0019)

Notes

${ }^{1}$ Long panel refers to the sample of wage growth measures computed over the entire observed careers of our NLSY respondents.

${ }^{2}$ Control variables: First real wage (and the log of first real wage in the second column), gender, race (nonwhite versus white), age, six schooling categories, AFQT scores, health status, average per capital neighborhood income, religion affiliation, and frequency of attendance of religious services. See the Data Appendix for a more detailed description of all variables. 


\section{Table 5}

\section{Wage Growth Regressions \\ OLS Smoking Coefficients \\ (Standard Errors in Parentheses) \\ Sample: Short panel ${ }^{1}$}

Wage growth measures based on

(i) Real wage $\quad$ (ii) Log of real wage

Cumulative Controls ${ }^{2}$

1. First Real Wage

$-.209$

$-.0245$

(.024)

(.0027)

2. Sex, Race \& Age

$-.237$

$-.0280$

(.023)

(.0027)

3. Schooling

$-.102$

$-.0124$

(.024)

(.0028)

4. AFQT

$-.087$

$-.0107$

$(.024)$

(.0028)

5. Health, Neighborhood

$-.088$

$-.0109$

Income, Religion

$(.024)$

(.0028)

Notes

${ }^{1}$ Short panel refers to the sample of wage growth measures computed over the first six years since entering the labor market.

${ }^{2}$ Control variables: First real wage (and the log of first real wage in the second column), gender, race (nonwhite versus white), age, six schooling categories, AFQT scores, health status, average per capital neighborhood income, religion affiliation, and frequency of attendance of religious services. See the Data Appendix for a more detailed description of all variables. 


\section{Table 6}

\section{Wage Growth Regressions \\ OLS Smoking Coefficients \\ (Standard Errors in Parentheses) \\ Sample: Short-Continuous panel ${ }^{1}$}

Wage growth measures based on

$\begin{array}{ll}\text { (i) Real wage } & \text { (ii) Log of real wage }\end{array}$

Cumulative Controls ${ }^{2}$

1. First Wage

$-.188$

$-.0191$

(.023)

(.0022)

2. Sex, Race \& Age

$-.212$

$-.0212$

(.023)

(.0022)

3. Schooling

$-.079$

$-.0078$

(.023)

(.0022)

4. AFQT

$-.063$

$-.0062$

$(.023)$

(.0022)

5. Health, Neighborhood

$-.067$

$-.0067$

Income, Religion

(.023)

(.0022)

Notes

${ }^{1}$ Short-Continuous panel refers to the sample of wage growth measures computed over the first six years since entering the labor market without any missing observations.

${ }^{2}$ Control variables: First real wage (and the log of first real wage in the second column), gender, race (nonwhite versus white), age, six schooling categories, AFQT scores, health status, average per capital neighborhood income, religion affiliation, and frequency of attendance of religious services. See the Data Appendix for a more detailed description of all variables. 
Table 7

Wage growth differences between non-smokers and smokers

$\underline{\text { Sample restrictions }}$

$\begin{array}{lll}\frac{\text { Real dollar differences }}{\text { Gross }} & \text { Real percentage differences } \\ & \text { Gross Net }\end{array}$

$\begin{array}{llll}\text { Long panel } & 62 \% & 24 \% & 48 \%\end{array}$

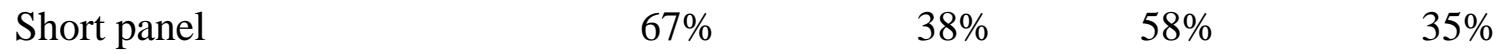

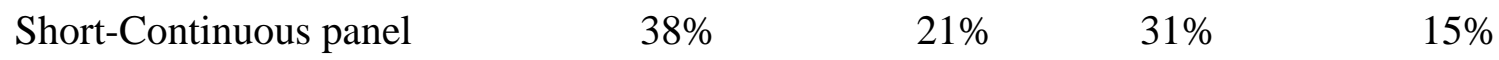

Notes. The above numbers represent the differences in wage growth between non-smokers and smokers as a percent of the mean wage growth of smokers. In the "Gross" column, the numerator is the difference in sample means (of wage growth) between non-smokers and smokers while the denominator is the mean value for smokers (see Table 2). In the "Net" column the numerator is the regression coefficient of the smoking dummy variable, (see tables 4-6) while the denominator is the mean value for smokers (see Table 2). The three rows represent data from the different sample restrictions we impose. 


\section{Table 8}

\section{Smoking Rates by College Majors* (Survey of College Majors 1999)}

\begin{tabular}{|c|c|c|c|c|c|}
\hline Major & Obs & $\begin{array}{l}\text { Number of } \\
\text { Smokers }\end{array}$ & $\begin{array}{l}\text { Smoker } 1 \\
\text { (SE) }\end{array}$ & $\begin{array}{l}\text { Smoker } 2 \\
(\mathrm{SE})\end{array}$ & $\begin{array}{l}\text { Prior } \\
\text { Smoker } \\
(\mathrm{SE})\end{array}$ \\
\hline Dance & 12 & 8 & $\begin{array}{l}.67 \\
(.136)\end{array}$ & $\begin{array}{l}.33 \\
(.136)\end{array}$ & $\begin{array}{l}.63 \\
(.171)\end{array}$ \\
\hline English & 21 & 10 & $\begin{array}{l}.48 \\
(.109)\end{array}$ & $\begin{array}{l}.24 \\
.093)\end{array}$ & $\begin{array}{l}.70 \\
(.145)\end{array}$ \\
\hline History & 14 & 6 & $\begin{array}{l}.43 \\
(.132)\end{array}$ & $\begin{array}{l}.14 \\
(.093)\end{array}$ & $\begin{array}{l}.33 \\
(.192)\end{array}$ \\
\hline Asian Studies & 10 & 4 & $\begin{array}{l}.40 \\
(.155)\end{array}$ & $\begin{array}{l}.20 \\
(.126)\end{array}$ & $\begin{array}{l}.25 \\
(.217)\end{array}$ \\
\hline Computer Science & 11 & 4 & $\begin{array}{l}.36 \\
(.145)\end{array}$ & $\begin{array}{l}.18 \\
(.116)\end{array}$ & $\begin{array}{l}.75 \\
(.271)\end{array}$ \\
\hline Economics & 120 & 40 & $\begin{array}{l}.33 \\
(.043)\end{array}$ & $\begin{array}{l}.13 \\
(.031)\end{array}$ & $\begin{array}{l}.43 \\
(.078)\end{array}$ \\
\hline Political Science & 23 & 7 & $\begin{array}{l}.30 \\
(.096)\end{array}$ & $\begin{array}{l}.22 \\
(.086)\end{array}$ & $\begin{array}{l}.29 \\
(.172)\end{array}$ \\
\hline Natural Science & 33 & 8 & $\begin{array}{l}.24 \\
(.074)\end{array}$ & $\begin{array}{l}.09 \\
(.050)\end{array}$ & $\begin{array}{l}.25 \\
(.153)\end{array}$ \\
\hline Engineering & 45 & 9 & $\begin{array}{l}.20 \\
(.060)\end{array}$ & $\begin{array}{l}.11 \\
(.047)\end{array}$ & $\begin{array}{l}.56 \\
(.165)\end{array}$ \\
\hline Psychology & 24 & 4 & $\begin{array}{l}.17 \\
(.077)\end{array}$ & $\begin{array}{l}.08 \\
(.055)\end{array}$ & $\begin{array}{l}1.0 \\
(0)\end{array}$ \\
\hline
\end{tabular}

\section{Notes}

* Results based on several hundred surveys of Barnard and Columbia College undergraduates. Only the top 10 majors are reported. Standard Errors (SE) are in parentheses and are calculated assuming binomial distribution.

\section{Definitions}

Smoker 1: If smoke 1 or more cigarettes per day.

Smoker 2: If smoke 5 or more cigarettes per day.

Prior Smoker: Fraction of current smokers (Smoker 1) who started smoking prior to coming to College (before age 18). 


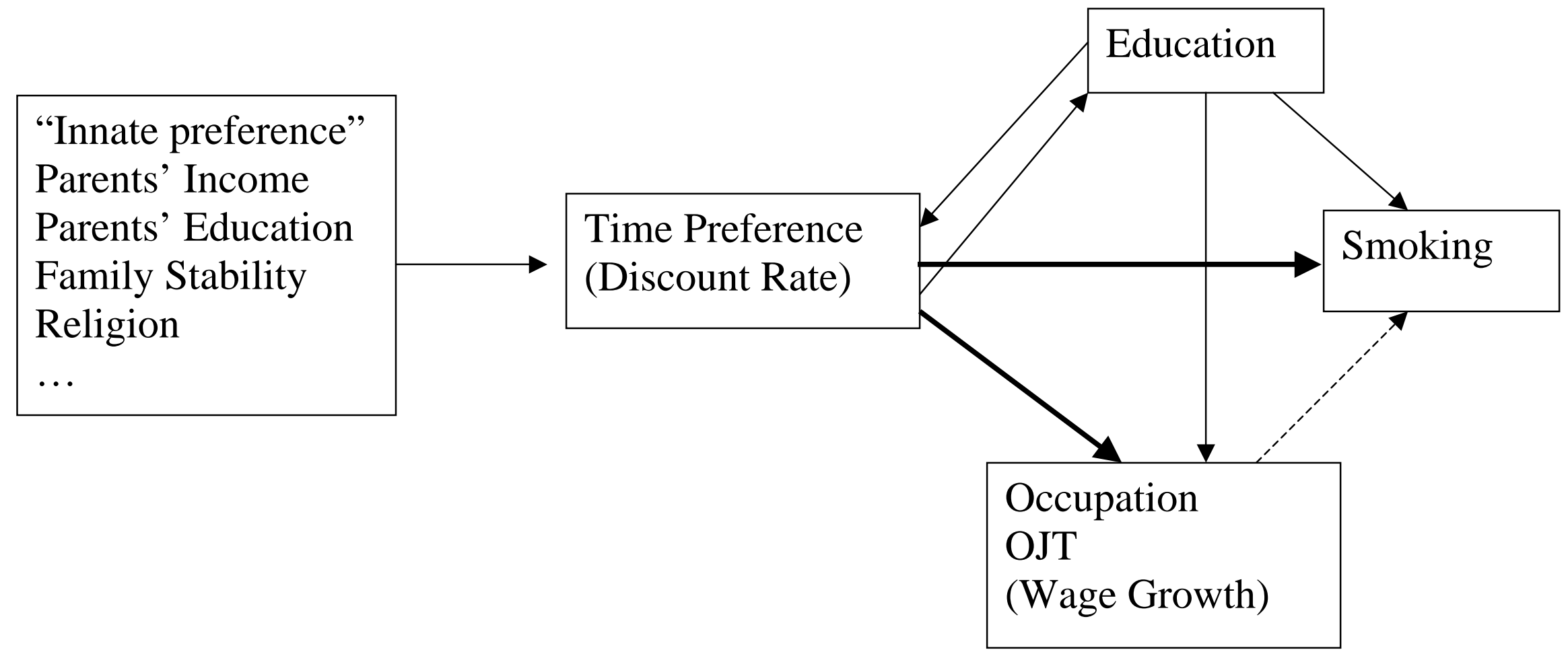

